\title{
32. ESTIMATING IN-SITU THERMAL CONDUCTIVITY FROM LOG DATA ${ }^{1}$
}

\author{
Heinrich W. Villinger, ${ }^{2}$ Marcus G. Langseth, ${ }^{3}$ Henrike M. Gröschel-Becker, ${ }^{4}$ and Andrew T. Fisher ${ }^{5}$
}

\begin{abstract}
Hole 857C, drilled in Middle Valley, northern Juan de Fuca Ridge, during Leg 139 of the Ocean Drilling Program, penetrated about $470 \mathrm{~m}$ of turbidite sediments. Below the sediments the hole intersected a series of basaltic sills interbedded with sediments. Hole $857 \mathrm{C}$ is located south of an active hydrothermal vent field in an area where seafloor heat flow measurements show values exceeding $0.8 \mathrm{~W} / \mathrm{m}^{2}$. This hole was successfully logged with the seismic and lithodensity tool string. Open-hole temperatures at a depth of $480 \mathrm{mbsf}$ are as high as $222^{\circ} \mathrm{C}$. The porosity profile of Hole $857 \mathrm{C}$, based on log-derived wet-bulk densities, forms the basis for the calculation of a thermal conductivity profile using a binary mixture of sediment grains and seawater and a geometric mean model. The thermal conductivity of the grains is assumed to be $2.6 \mathrm{~W} / \mathrm{m}-\mathrm{K}$ (Davis and Seeman, this volume). High temperatures encountered in Hole $857 \mathrm{C}$ require that temperature effects on the thermal conductivity must be included. The variation of the thermal conductivity of seawater is well known. The decrease of the thermal conductivity of the grains with increasing temperature is calculated after Sass et al. (1992) and Chapman et al. (1984). A purely conductive vertical heat flow is assumed to allow the iterative modeling procedure caused by the nonlinear nature of the problem. The model calculations show that the results of a simple model with constant thermal parameters are similar to those of a model that includes a temperature-dependent seawater thermal conductivity and temperature coefficient of the grain thermal conductivity after Sass et al. (1992). This surprising result is a consequence of the competing effects of decreasing porosity with depth, decreasing thermal conductivity of the grains with depth (and temperature), and the variation of the thermal conductivity of seawater with temperature. Results based on temperature corrections of Chapman et al. (1984) give unrealistically high temperatures at the base of the sediments. Varying the grain thermal conductivity between 2.6 and $3.2 \mathrm{~W} / \mathrm{m}-\mathrm{K}$ results in a range of thermal conductivity profiles that predict temperatures that are in agreement with observed vent fluid temperatures.
\end{abstract}

\section{INTRODUCTION}

One of the primary goals of Ocean Drilling Program (ODP) Leg 139 was the investigation of the hydrothermal regime of Middle Valley, northern Juan de Fuca Ridge. Deep-tow camera observations and observations from submersibles had revealed localized hydrothermal venting confined to small areas. Seafloor heat flow measurements allowed the estimation of temperature at depth under the assumption of purely conductive vertical heat flow (Davis and Villinger, 1992). Anomalous pore-fluid composition obtained from measurements on pore-fluid samples from gravity cores (J. Lydon, pers. comm., 1991) indicated that a measurable advective heat transport component caused by diffuse upward fluid flow was locally present. In drill holes, therma anomalies associated with advective heat transport can be detected as depth variations in measured heat flow. Detailed knowledge of thermal conductivity and temperature structure in the formation around the hole would be required for this analysis; however, this information is not available for the holes drilled during Leg 139. In this paper we attempt to derive a detailed thermal conductivity profile for Hole $857 \mathrm{C}$ using available log data.

Site 857 is located about $1.6 \mathrm{~km}$ south of an active vent field, where hot fluids discharge through the seafloor at temperatures of up to $276^{\circ} \mathrm{C}$ (Shipboard Scientific Party, 1992). Conductive heat flow from conventional heat flow measurements has values exceeding 0.8 $\mathrm{W} / \mathrm{m}^{2}$ (Davis and Villinger, 1992). The sedimentary cover at Site 857

\footnotetext{
${ }^{1}$ Mottl, M.J., Davis, E.E., Fisher, A.T., and Slack, J.F. (Eds.), 1994. Proc. ODP, Sci. Results, 139: College Station, TX (Ocean Drilling Program).

${ }^{2}$ University of Bremen, P.O. Box 330440,2800 Bremen 33, Germany.

${ }^{3}$ Lamont-Doherty Earth Observatory, Columbia University, Palisades, New York 10964, U.S.A.

${ }^{4}$ Division of Marine Geology and Geophysics, Rosenstiel School of Marine and Atmospheric Science, University of Miami, 4600 Rickenbacker Causeway, Miami, FL 33149-1098, U.S.A.

${ }^{5}$ Ocean Drilling Program, Texas A\&M University Research Park, 1000 Discovery Drive, College Station, TX 77845-9547, U.S.A. (Present address: Department of Geological Sciences and Indiana Geological Survey, Indiana University, 611 North Walnut Grove, Bloomington, IN 47405-2862, U.S.A.)
}

is on the order of $500 \mathrm{~m}$ thick and consists of semiconsolidated turbidites, mainly siltstones, fine-grained sandstone layers, and interbedded silty claystones. The highest priority at this site was to test the conceptual model of a hydrothermal reservoir located in the uppermost part of the igneous crust. Because of the impermeable nature of the sediment cover, it was anticipated that vertical advective water transport through the sediments is of minor importance and therefore heat transfer is predominantly conductive. Results from the porewater geochemistry confirmed this assumption but also revealed substantial lateral water movement (Shipboard Scientific Party, 1992).

Holes $857 \mathrm{~A}$ and $857 \mathrm{~B}$, drilled at almost identical positions, penetrated only the upper $111 \mathrm{~m}$ of the impermeable sediment cover. Hole $857 \mathrm{C}$ was an exploratory hole that penetrated the complete section of sediments to a depth of $471 \mathrm{mbsf}$ and was deepened through an alternating sequence of sills and sediments to a final depth of $568 \mathrm{mbsf}$. This hole was logged, then cemented after the completion of all operations. Hole $857 \mathrm{D}$, about $100 \mathrm{~m}$ northeast of Hole $857 \mathrm{C}$, reached a final depth of $936 \mathrm{mbsf}$ in the continuing sequence of alternating sill/sediment layers. The comparison of temperature logs in Hole $857 \mathrm{C}$ and 857D indicates that a strong drawdown was present at Hole 857D. Downhole flow measurements showed that the major drawdown occurs within the sediment-sill complex between $610 \mathrm{mbsf}$ and $615 \mathrm{mbsf}$ (Becker et al., this volume; Shipboard Scientific Party, 1992).

Hole $857 \mathrm{C}$ was logged successfully with the seismic and lithodensity tool string. Geochemical logs are not available due to technical problems. In the unconsolidated sediment section of Holes 857A, $857 \mathrm{~B}$, and $857 \mathrm{C}$ down to a depth of $113 \mathrm{mbsf}$, formation temperatures could be derived from measurements made with the water sampler and temperature probe (WSTP) and advanced hydraulic piston core (APC) temperature tool. Below that depth all temperature profiles show the cooling effect of the drilling operation and do not reflect true formation temperatures. Physical properties measurements were made on board on samples from all holes (Shipboard Scientific Party, 1992).

In this paper we use log-derived wet-bulk density data to estimate the detailed thermal conductivity structure within the sediment section of Hole 857C. This estimate is calculated on the basis of existing empirical models relating bulk thermal conductivity to sedi- 
ment porosity and the thermal conductivity of matrix components. The inferred thermal conductivity structure is used to estimate temperatures at depth under the simplifying assumption of a purely conductive thermal regime. High temperatures encountered in Hole $857 \mathrm{C}$ complicate the calculation of the thermal conductivity structure as temperature effects on physical properties must be included. This requires an iterative calculation scheme. Temperature logs made in Hole $857 \mathrm{C}$ during Leg 139 do not reflect true formation temperatures but are used as minimal temperatures to constrain the different thermal conductivity models.

\section{CALCULATION OF POROSITY STRUCTURE FOR HOLE 857C}

The high-temperature lithodensity tool (HLDT) is part of the ODP standard logging suite. Medium-energy gamma rays are emitted into the formation via an excentered sidewall skid. These gamma rays collide with electrons in the formation, resulting in Compton scattering, which is recorded via a gamma ray sensor in the pad. Electron density is then converted to bulk density. Figure 1A shows the wet-bulk density of the sediment section for a depth range of 100 to $470 \mathrm{mbsf}$ just above the first sediment-sill interface. Over this range, density increases from values around $1.80 \mathrm{~g} / \mathrm{cm}^{3}$ to $2.25 \mathrm{~g} / \mathrm{cm}^{3}$. Superimposed on this general trend are meter-scale variations in which density varies by typically $\pm 0.05 \mathrm{~g} / \mathrm{cm}^{3}$, reflecting the variable thickness and internal porosity structure of the turbidites. The individual data points from above $100 \mathrm{mbsf}$ shown in Figure 1A come from measurements of core samples from Holes $857 \mathrm{~A}$ and $857 \mathrm{C}$, which are not rebound corrected, but fit well in the general trend of the extrapolated logging data. As the pad of the HLDT is pressed against the borehole wall, it provides a good estimate of the true formation wet-bulk density within zones over which the nuclear source and detector make contact with the formation. Conditions in Hole $857 \mathrm{C}$ were normally excellent, making the HLDT data set extremely reliable. We used the HLDT data to calculate the porosity as

$$
\phi(z)=\frac{\rho_{m}-\rho_{\mathrm{HLDT}}(z)}{\rho_{m}-\rho_{f}(T[z])}
$$

where $z$ is the depth in mbsf, $T(z)$ is the temperature in ${ }^{\circ} \mathrm{C}, \rho(z)$ is the fractional porosity, $\rho_{m}$ is the density of the matrix in $\mathrm{g} / \mathrm{cm}^{3}, \rho_{\text {HLDT(z) }}$ is density data from the log in $\mathrm{g} / \mathrm{cm}^{3}$, and $\rho f(T[z])$ in $\mathrm{g} / \mathrm{cm}^{3}$ is the density of the pore-filling fluid as a function of temperature.

Grain density was calculated from volume and weight measurements on dried sediment samples. A constant value of $\rho_{m}=2.78 \mathrm{~g} / \mathrm{cm}^{3}$ is used for the porosity calculation as this value shows little variation over the depth range of the sediments in Hole 857C (Shipboard Scientific Party, 1992).

We assume that the pore-filling fluid in all cases is seawater (Shipboard Scientific Party, 1992) as represented by a 0.564 molality $\mathrm{NaCl}$ (concentration of $3.2 \%$ ) solution (Bischoff and Rosenbauer, 1984). The decrease of seawater density with increasing temperature is calculated for a fixed pressure of $30 \mathrm{MPa}$ (Phillips et al., 1981), which is roughly equivalent to a water depth of $3000 \mathrm{~m}$ :

$$
\rho_{f}(T)=1.056-0.000434 \cdot T-1.689 \cdot 10^{-6} T^{2}
$$

The density increase with pressure of seawater is about 0.00084 $\left(\mathrm{g} / \mathrm{cm}^{3}\right) / \mathrm{MPa}$ (Phillips et al., 1981) at $30 \mathrm{MPa}$. The maximum error in a 500-m-deep drill hole at a water depth of $3000 \mathrm{~m}$ would only amount to $0.004 \mathrm{~g} / \mathrm{cm}^{3}$, which represents approximately a $0.4 \%$ increase in the case of Hole $857 \mathrm{C}$. Therefore, the pressure effect on the density will be ignored. Figure 1B shows seawater density as a function of temperature. For comparison, data for pure water (Phillips et al., 1981) are shown for discrete temperatures as well.
In order to use Equations 1 and 2 to calculate porosity as a function of depth, we need a temperature vs. depth profile for Hole $857 \mathrm{C}$. In-situ temperatures measured in the unconsolidated upper part of Hole $857 \mathrm{C}$ when combined with thermal conductivity measurements on cores yield a conductive heat flow of $803 \mathrm{~mW} / \mathrm{m}^{2}$ (Shipboard Scientific Party, 1992). We have extrapolated shallow temperatures to the first sediment-sill interface by assuming a purely conductive regime and a thermal conductivity profile that was based on a linear fit of measured sample thermal conductivities within the sediments (Shipboard Scientific Party, 1992). Figure 1C shows the measured and extrapolated temperatures at Site 857.

This initial temperature distribution is used with Equations 1 and 2 to calculate a porosity profile for Hole $857 \mathrm{C}$ (Fig. 1D). A secondorder polynomial used to approximate the decrease of fractional porosity with depth is later used as initial guess for the thermal conductivity model calculations. As the log data start at about 100 mbsf, uncorrected laboratory porosities from core samples are combined with the log data to produce a composite set (Fig. 1D). Despite the large scatter in the sample porosities, the second-order polynomial based on log data tracks these shallow measurements well.

\section{THERMAL CONDUCTIVITY MODELS AND DATA}

The bulk thermal conductivity of a sedimentary rock depends on mineralogy, grain size, grain shape, grain arrangement, porosity, and pore-filling material. Theoretical formulas have been developed and tested that allow the calculation of the bulk thermal conductivity based on the composition of rock (i.e., Drury and Jessop, 1983; Williams and Anderson, 1990; Kovalenko and Flanders, 1991). Experimental investigations (i.e., Woodside and Messmer, 1961; Brigaud and Vasseur, 1989) show that a geometric mean model is often adequate for computing the thermal conductivity of heterogeneous media:

$$
k=\prod_{i=1}^{n} k_{i}^{V_{i}}
$$

where $k_{i}$ is the thermal conductivity of the constituent and $V_{i}$ is its fractional volume. In the case of the hemipelagic sediments encountered in all Leg 139 holes, the problem of calculating the bulk thermal conductivity can be reduced to the calculation of the thermal conductivity of a mixture of seawater, mixed layer clay, quartz, and feldspar (Davis, Mottl, Fisher, et al., 1992):

$$
k=k_{S}^{V_{s}} k_{\varrho}^{V^{\varrho}} k_{F}^{V_{F}} k_{C}^{V_{C}}
$$

where $k_{S}$ is the thermal conductivity of seawater, $k_{Q}$ is the thermal conductivity of quartz, $k_{F}$ is the thermal conductivity of feldspar, $k_{C}$ is the thermal conductivity of mixed layer clays, and $V$ represents the fractional volume of each constituent. All other constituents of noncalcareous marine sediments are of minor importance for the calculation of the thermal conductivity as they form only a small fraction of the total volume of the sediment. In order to be able to use Equation $4 \mathrm{~A}$, the composition of the sediments has to be known with reasonable accuracy. As no data on the volumetric sediment grain composition from Hole $857 \mathrm{C}$ is available, we will use the simple model of a binary mixture of sediment grains and seawater to calculate the thermal conductivity of the sediment:

$$
k=k_{f}^{\phi} k_{G}^{(l-\phi)}
$$

where $k_{f}$ is the thermal conductivity of seawater, $k_{G}$ is the thermal conductivity of the sediment grains and $\phi$ the fractional porosity. Equation $4 \mathrm{~B}$ is used throughout remainder of this chapter to calculate the thermal conductivity of sediments at Hole 857C.

Numerous thermal conductivity measurements made on samples from Sites $855,856,857$ and 858 during Leg 139 allow a grain 

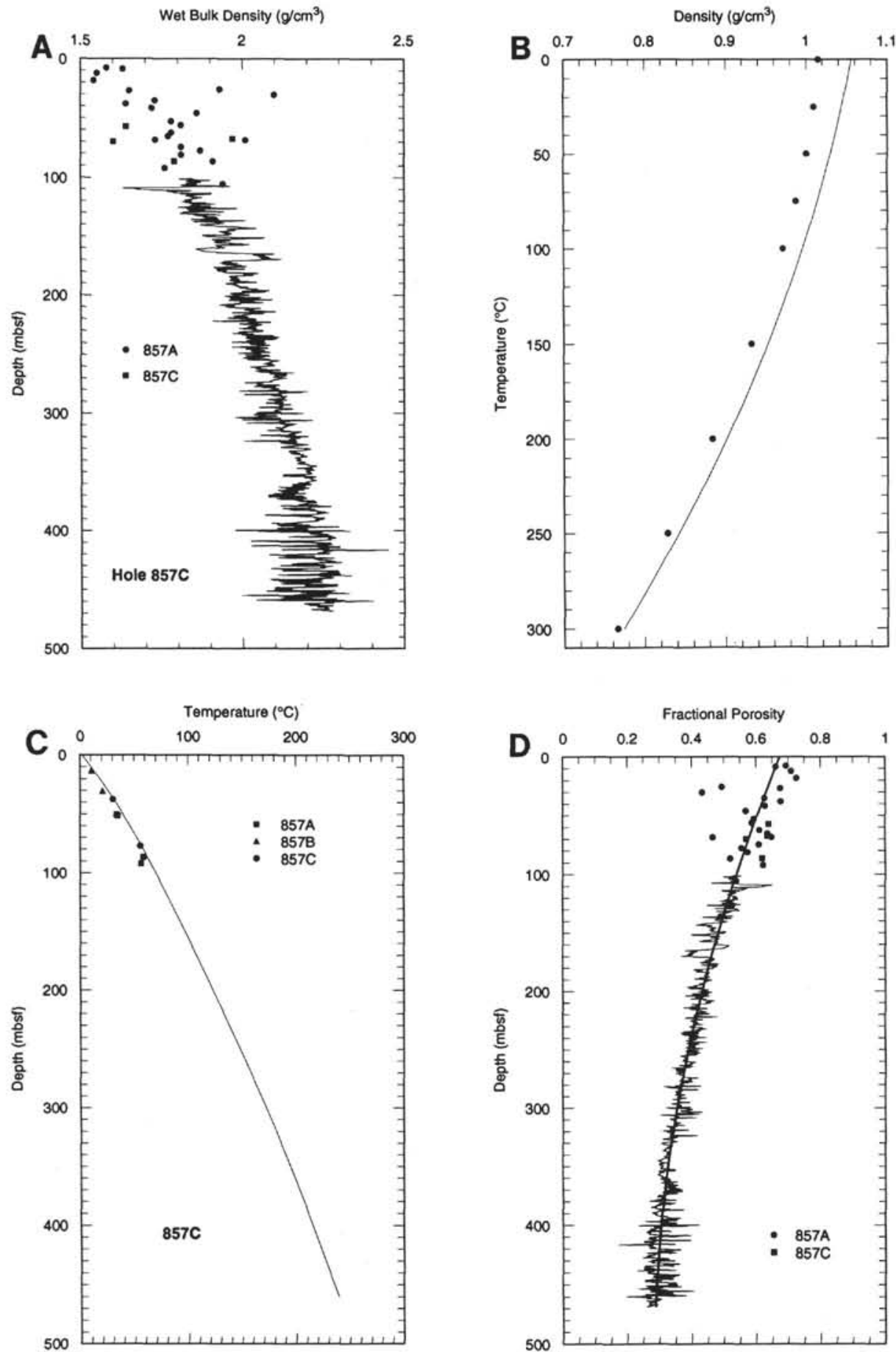

Figure 1. A. Wet-bulk density of Hole 857C, measured with the lithodensity tool. The sample porosities from Hole 857A (solid circles) and 857C (solid squares) are shown for comparison. These data were measured under laboratory conditions and are not corrected for in-situ pressure or temperature. B. Density of 0.564 $\mathrm{mol} \mathrm{NaCl}$ solution as a function of temperature at a constant pressure of $30 \mathrm{MPa}$ (Phillips et al., 1981). The decrease of the density of pure water (solid spheres) is shown for comparison. C. Estimated temperature profile in Hole 857C. The individual data points represent temperature measurements made with the APC temperature tool (Shipboard Scientific Party, 1992) in Holes 857A, B, and C. The solid line represents extrapolated temperatures at depth, calculated on the basis of a purely conductive vertical heat flow of $0.803 \mathrm{~mW} / \mathrm{m}^{2}$ and a linear fit of measured sample thermal conductivities (Shipboard Scientific Party, 1992). D. Calculated fractional porosity profile for Hole $857 \mathrm{C}$ using a measured grain density of $2.78 \mathrm{~g} / \mathrm{cm}^{3}$ and a temperature-dependent density of seawater. The solid line represents a least-squares fitted second order polynomial of the calculated porosities, where $\phi(z)=0.682-0.00155 z+1.53 \cdot 10^{-6} z^{2}$. Sample porosity measurements from Hole 857A (solid spheres) and Hole 857C (solid squares) are shown for comparison (Shipboard Scientific Party, 1992). These data were measured under laboratory conditions and are not corrected for in-situ pressure or temperature. 
thermal conductivity to be derived in those cases where the sample porosity is known as well. The resulting grain thermal conductivities are in a range from 3.12 to $3.9 \mathrm{~W} / \mathrm{m}-\mathrm{K}$ (Davis, Mottl, Fisher, et al., 1992). The variation is unexpectedly high as there is no indication from other data that the sediments differ substantially in their composition from site to site. Divided-bar laboratory measurements of thermal conductivity of semiconsolidated sediments from Leg 139 by Davis and Seeman (this volume) show that the sediments have a highly anisotropic thermal conductivity and have a vertical grain thermal conductivity of $2.6 \mathrm{~W} / \mathrm{m}-\mathrm{K}$, a value substantially lower than those published in Davis, Mottl, Fisher, et al. (1992). These conflicting results may be due to problems associated with the needle probe instrument used on board to measure the thermal conductivity and the anisotropy of the samples. Because the results of Davis and Seeman (this volume) have a higher reliability due to the measurement technique used, and because we assume a purely vertical heat flow, we will use a vertical grain thermal conductivity of $2.6 \mathrm{~W} / \mathrm{m}-\mathrm{K}$ unless otherwise indicated.

The thermal conductivity of rocks at temperatures up to about $300^{\circ} \mathrm{C}$ decreases or increases depending on the composition of the rocks (Birch and Clark, 1940). For example, crystalline quartz or carbonates have a negative temperature coefficient whereas glasses have positive coefficients. Feldspars and mafic minerals show almost no variation in their thermal conductivity with increasing temperature. Experimental investigations on the thermal properties of clay-rich sediments are extremely limited, mainly because clays and semiconsolidated claystones are extremely difficult to handle in experimental studies. Morin and Silva (1984) conducted the only study of thermal conductivity of ocean sediments under pressure and temperature. However, all their samples had porosities ranging from $60 \%$ to $70 \%$; thus most of the physical properties are dominated by the properties of the pore-filling fluid (i.e., seawater). An extrapolation of their results to typical Hole $857 \mathrm{C}$ porosities ranging from $40 \%$ to $20 \%$ is not justified; therefore the temperature coefficient of clays and clay-rich sediments is not known. The data from Birch and Clark (1940) measured on low-porosity rocks show that the thermal conductivity decrease is proportional to the reciprocal temperature and the magnitude of the decrease is proportional to the absolute value of the thermal conductivity at room temperature. We will discuss two published correction formulae which will be used later to calculate the temperature effects of the sediment matrix thermal conductivity.

Sass et al. (1992) developed an empirical correction based on the data set of Birch and Clark (1940):

$$
k_{m}(T)=\frac{k_{m(o)}}{1.007+T\left(0.0036-\frac{0.0072}{k_{m(o)}}\right)}
$$

and

$$
k_{m(o)}=k_{m(25)}\left(1.007+25\left(0.0037-\frac{0.0074}{k_{m(25)}}\right)\right)
$$

where $k_{m(o)}$ is the thermal conductivity of the rock matrix at $0^{\circ} \mathrm{C}, k_{m(25)}$ is the thermal conductivity of the rock matrix at $25^{\circ} \mathrm{C}$, and $T$ is the temperature in ${ }^{\circ} \mathrm{C}$. Sass et al. (1992) do not explicitly specify the temperature and conductivity range for which their formula is valid. A careful examination of Equation 5 shows that the lower bound in thermal conductivity is $2 \mathrm{~W} / \mathrm{m}-\mathrm{K}$, for which their formula results in a zero temperature coefficient. The temperature range for Equation 5 is assumed to be $0^{\circ}-300^{\circ} \mathrm{C}$ as Sass et al. (1992) show that their formula is valid beyond $200^{\circ}$; the data set by Birch and Clark (1940), however, in most cases covers only temperatures up to $200^{\circ} \mathrm{C}$.
Chapman et al. (1984) use the following formula to apply a temperature correction to the solid matrix conductivity without explicitly basing their approach on experimental data. Their formula is also used in a subsequent paper by Brigaud et al. (1990):

$$
k_{m}(T)=k_{m(20)}\left(\frac{293}{273+T}\right)
$$

where $k_{m}(T)$ is the temperature-corrected thermal conductivity of the rock matrix, $k_{m(20)}$ is the thermal conductivity of the rock matrix at $20^{\circ} \mathrm{C}$, and $T$ is the temperature in ${ }^{\circ} \mathrm{C}$.

Figure 2 shows a comparison of Equations 5 and 6 . The formula by Chapman et al. (1984) predicts a much stronger decrease than that published by Sass et al. (1992). Both equations will be used as end members for the thermal conductivity correction. Pressure effects on thermal conductivity of rocks are much smaller than temperature effects in the pressure ranges expected for Hole $857 \mathrm{C}$, as indicated by results for crystalline quartz (Horai and Susaki, 1989). Therefore, pressure effects on thermal conductivity will be ignored throughout this work.

The thermal conductivity of pure water with increasing temperature and pressure is well known (Phillips et al. (1981)). Figure 3A shows a part of the experimental data set of Yusufova et al. (1978) for saline solutions compared with the thermal conductivity of pure water (Phillips et al. (1981)) at $30 \mathrm{MPa}$. The data for salt water follow the general trend of pure water well with a small offset that increases slightly with temperature. A parabolic fit to the data for salt water $(0.564 \mathrm{~mol} \mathrm{NaCl}$ solution or $3.2 \%)$ gives:

$$
K_{f}=0.569+1.605 \cdot 10^{-3} T-5.8 \cdot 10^{-6} T^{2}
$$

where $k_{f}$ is the thermal conductivity of $3.2 \% \mathrm{NaCl}$ solution (equivalent to seawater) and $T$ is temperature in ${ }^{\circ} \mathrm{C}$. In contrast to the temperature effect for minerals, the temperature effect for water results in an increase from $0^{\circ} \mathrm{C}$ to $150^{\circ} \mathrm{C}$ at $25-35 \mathrm{MPa}$ and a decrease from $150^{\circ} \mathrm{C}$ to $300^{\circ} \mathrm{C}$. The pressure dependence of water thermal conductivity (Fig. 3B) reaches a maximum of $1.6 \cdot 10^{-3}(\mathrm{~W} / \mathrm{m}-\mathrm{K}) / \mathrm{MPa}$ at $300^{\circ} \mathrm{C}$ in the pressure range of $25-35 \mathrm{MPa}$ (approximately equivalent to a water depth of 2500 to $3500 \mathrm{~m}$ ). Once again, this pressure dependence of the thermal conductivity of seawater is less significant than the thermal effects and will therefore be ignored.

\section{RESULTS OF THERMAL CONDUCTIVITY MODEL CALCULATIONS}

The in-situ thermal conductivity in Hole $857 \mathrm{C}$ must be calculated iteratively as the problem is nonlinear due to the temperature dependence of the relevant physical parameters. A simple transformation as suggested by Carslaw and Jaeger (1959) is only valid for regions with constant thermal conductivity and is not applicable in our case. We also must make assumptions about the underlying heat transport process to be able to calculate the temperature-depth profile. Advective transport of heat is likely to occur in Middle Valley (Davis, Mottl, Fisher, et al., 1992) but was not detected at Holes 857A, 857B, or $857 \mathrm{C}$ within the sediment section. The assumption of pure vertical conduction allows a temperature depth profile to be calculated in an analytical and simple way:

$$
T(z)=T_{s}+q \int_{0}^{z} \frac{d z^{\prime}}{k\left(z^{\prime}\right)}
$$

where $T(z)$ is temperature in ${ }^{\circ} \mathrm{C}$ vs. depth $\mathrm{z}, T_{s}$ is the temperature at the seafloor $\left({ }^{\circ} \mathrm{C}\right), \mathrm{q}$ is the vertical conductive heat flow in $\left(\mathrm{W} / \mathrm{m}_{2}\right)$, and $k(z)$ is thermal conductivity in (W/m-K) vs. depth. 


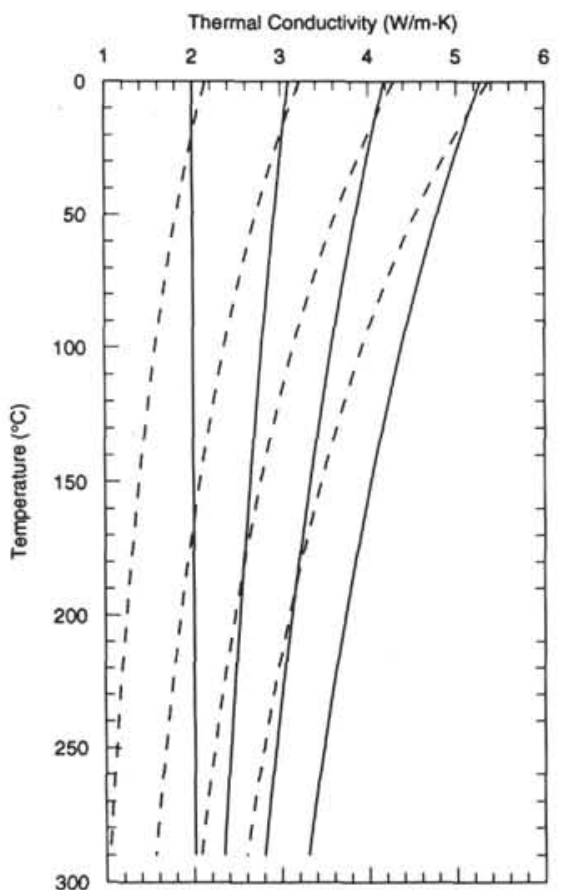

Figure 2. Predicted decrease of thermal conductivity of rocks with increasing temperature after Sass et al. (1992) (solid lines) and Chapman et al. (1984) (dashed lines). The lines show the change in thermal conductivities of 2, 3, 4 and $5 \mathrm{~W} /(\mathrm{m}-\mathrm{K})$ at laboratory temperatures.
The iteration scheme can be described as follows:

Step 1. Assume an initial temperature profile for the formation. Step 2. Calculate a porosity profile using Equations 1 and 2.

Step 3. Calculate a thermal conductivity profile using a geometric mean model.

Step 4. Calculate a conductive temperature profile using Equation 8.

Step 5. Compare the newly calculated temperature profile to the old temperature profile; if the temperature difference between iterations at any depth level is greater than $0.01^{\circ} \mathrm{C}$, repeat steps $2-5$. This scheme is similar to that of Nobes et al. (1986). The method converges rapidly to a stable temperature profile after about five iterations.

In the following we will discuss the results of four model calculations that represent end members with respect to the assumed temperature coefficient of the thermal conductivity. All models are binary mixtures of mineral grains and seawater, and are calculated with a constant grain thermal conductivity of $2.6 \mathrm{~W} / \mathrm{m}-\mathrm{K}$ at $20^{\circ} \mathrm{C}$ as discussed before. The models are organized in such a way that the temperature influence on the calculated thermal conductivity is progressively increasing. All calculations are based on a geometric mean model (Eq. 4B) and purely conductive vertical heat flow of $0.803 \mathrm{~W} / \mathrm{m}^{2}$. Model 0 represents an extreme case, as both constituents of the mixture have no temperature-dependent properties. In Model 1, only the thermal conductivity of seawater varies with temperature as described in Equation 7. Model 2 and Model 3 incorporate a temperature-dependent thermal conductivity of the matrix, with Model 2 calculated on the basis of Sass et al. (1992) (Eq. 5) and Model 3 according to Chapman et al. (1984) (Eq. 6).

All results of the four models described above are illustrated in Figures $4 \mathrm{~A}$ to $4 \mathrm{C}$. The porosity profiles of all four models are nearly
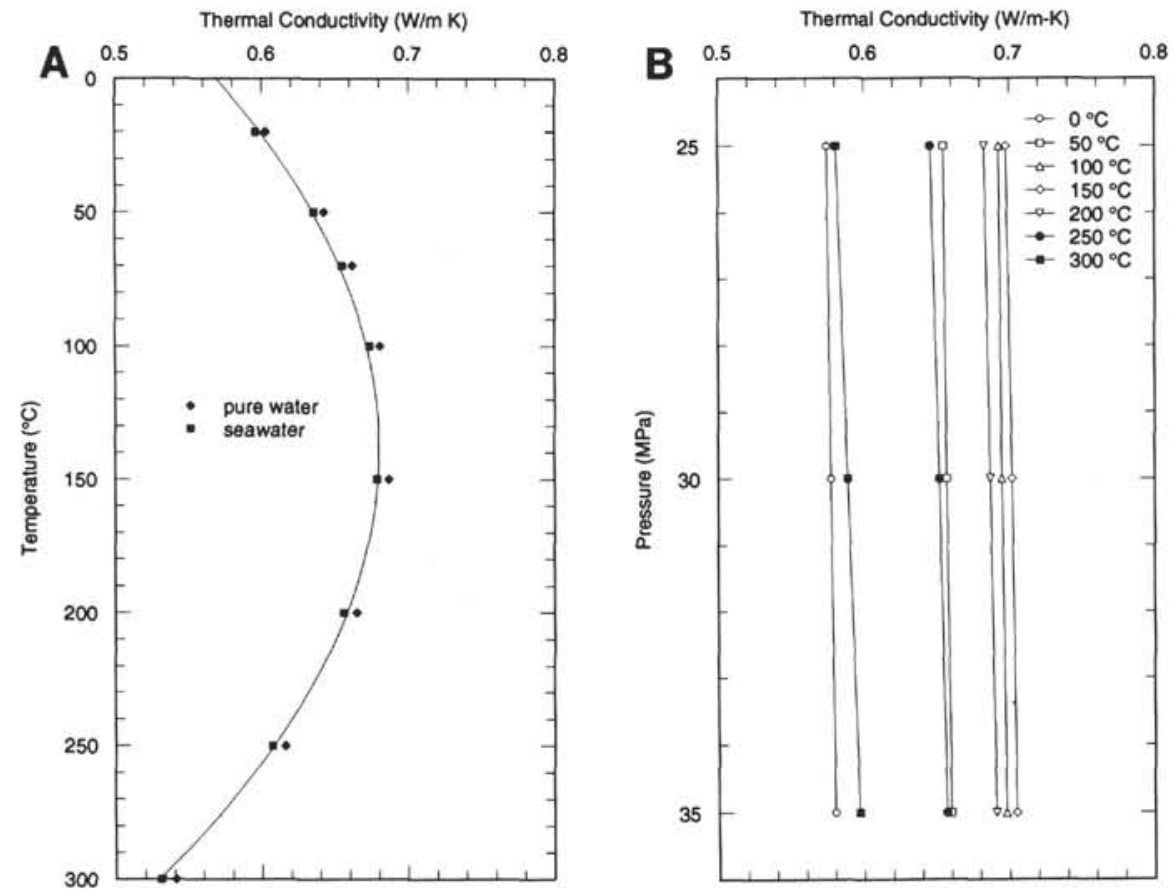

Figure 3. A. Thermal conductivity of $0.564 \mathrm{~mol} \mathrm{NaCl}$ solution (seawater) as a function of temperature at a pressure of $30 \mathrm{MPa}$ (Phillips et al., 1981). A second-degree polynomial (see Eq. 2) is used in the model calculations of thermal conductivity. The solid diamonds represent the thermal conductivity of pure water and the solid squares represent data from Phillips et al. (1981). B. The increase of thermal conductivity with pressure at selected temperatures (Phillips et al., 1981). The pressure coefficient increases from $5 \cdot 10^{-4}(\mathrm{~W} /[\mathrm{m}-\mathrm{K}]) / \mathrm{MPa}$ at $0^{\circ} \mathrm{C}$ to $16 \cdot 10^{-4}(\mathrm{~W} /[\mathrm{m}-\mathrm{K}]) / \mathrm{MPa}$ at $300^{\circ} \mathrm{C}$. 

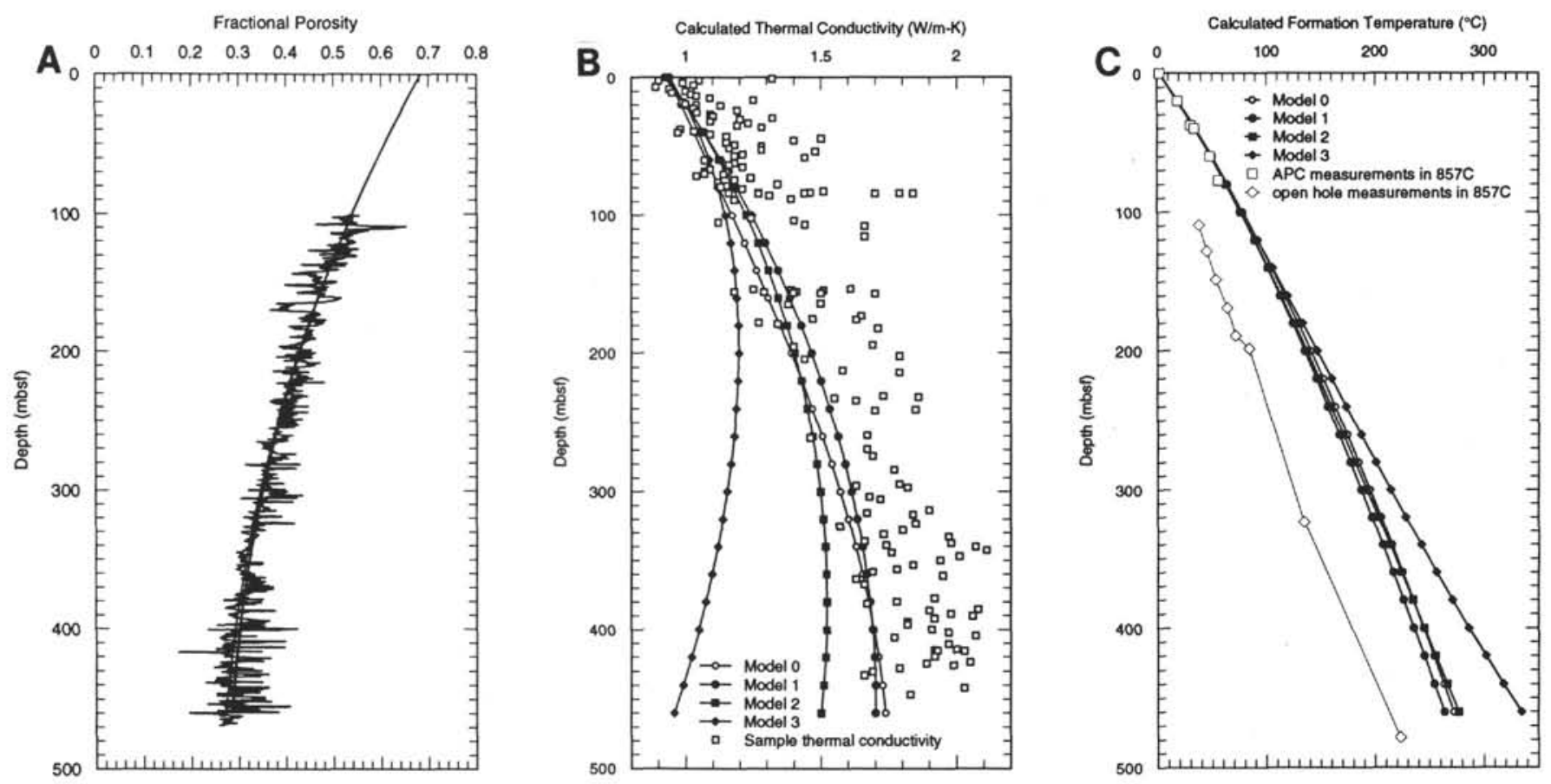

Figure 4. A. Calculated fractional porosity profiles, based on a grain thermal conductivity of $2.6 \mathrm{~W} /(\mathrm{m}-\mathrm{K})$ and the assumptions of thermal behavior of the models as described in the text. The results show that the porosity profile changes little with the assumed thermal behavior. Superimposed on the calculated results are the $\log$-derived porosities (see also Figure 1d). B. Calculated thermal conductivity profiles based on a grain thermal conductivity of $2.6 \mathrm{~W} /(\mathrm{m}-\mathrm{K})$ and the assumptions of thermal behavior of the models as described in the text. The open squares show measured and uncorrected sample thermal conductivities (Shipboard Scientific Party, 1992). Model 0 represents a model with no temperature-dependent thermal parameters whereas Model 3 reflects the strong decrease of the grain thermal conductivity as suggested by Chapman et al. (1984). C. Calculated temperature profiles, based on a grain thermal conductivity of $2.6 \mathrm{~W} /(\mathrm{m}-\mathrm{K})$ and the assumptions of thermal behavior of the models as described in the text. The open squares represent true formation temperatures, measured in the unconsolidated sediments of Hole 857C (Shipboard Scientific Party, 1992). Open-hole temperature measurements (open diamonds; Shipboard Scientific Party, 1992) are substantially lower than true formation temperatures but can serve as lower bounds for the model calculations.

identical (Fig. 4A) because the temperatures of the models differ the most at depths where the porosity is low and the effect of the temperature on the porosity calculation (Eq. 1) is small. The comparison of the calculated and log-derived porosity profile shows that all models well represent the general porosity decrease with depth. The almost identical porosity profiles result in different in-situ thermal conductivity profiles for the four models. The shapes of the profiles (Fig. 4B) are a superposition of the decreasing porosity, the decreasing thermal conductivity of the grains with depth (temperature), and the changing thermal conductivity of seawater (Fig. 3A). All models have thermal conductivities around $0.9 \mathrm{~W} / \mathrm{m}-\mathrm{K}$ at the seafloor, a value slightly smaller than the laboratory measurements on samples (Fig. 4B and Shipboard Scientific Party, 1992).

Model 0, with no temperature-dependent thermal parameters, shows a steady increase of thermal conductivity with depth up to a value of $1.8 \mathrm{~W} / \mathrm{m}-\mathrm{K}$ at $460 \mathrm{mbsf}$. The temperature-dependent thermal conductivity of seawater in Model 1 results in a slightly higher thermal conductivity than in Model 0 due to the initial increase of the thermal conductivity of seawater up to temperatures of about $150^{\circ} \mathrm{C}$ (Fig. 3A), which is equivalent to a depth of about $200 \mathrm{mbsf}$. The thermal conductivity is $1.5 \mathrm{~W} / \mathrm{m}-\mathrm{K}$ at this depth; at greater depths (higher temperatures) it increases more slowly, reaching about 1.7 $\mathrm{W} / \mathrm{m}-\mathrm{K}$ at the final depth of $460 \mathrm{mbsf}$. The thermal conductivities of Model 2, calculated on the basis of Sass et al. (1992), are lower than the values of Model 1 and lower than those of Model 0 below 240 mbsf. The thermal conductivities predicted by Model 2 rise to a maximum value of $1.52 \mathrm{~W} / \mathrm{m}-\mathrm{K}$ at $380 \mathrm{mbsf}$, then decrease to 1.5 $\mathrm{W} / \mathrm{m}-\mathrm{K}$ at $460 \mathrm{mbsf}$. Model 3 reflects the extreme decrease of the matrix conductivity with increasing temperature as calculated after Chapman et al. (1984). The thermal conductivities of Model 3 are already lower than all other conductivities at a depth of $100 \mathrm{mbsf}$. Values reach a maximum of $1.2 \mathrm{~W} / \mathrm{m}-\mathrm{K}$ at about $200 \mathrm{mbsf}$, then decrease to $0.95 \mathrm{~W} / \mathrm{m}-\mathrm{K}$ at $460 \mathrm{mbsf}$, a value almost identical to the calculated thermal conductivity of the sediments at the seafloor.

The temperature profiles, calculated using Model 0, Model 1, and Model 2 conductivities do not differ significantly (Fig. 4C). Calculated temperatures at $460 \mathrm{mbsf}$ range from $263^{\circ} \mathrm{C}$ to $287^{\circ} \mathrm{C}$. Only the profile of Model 3 gives significantly higher temperatures below a depth of about $250 \mathrm{mbsf}$ and reaches a final temperature of $334^{\circ} \mathrm{C}$ at 460 mbsf. The higher temperatures in Model 3 are a consequence of the lower thermal conductivities.

The validity of the calculated thermal conductivity models is difficult to assess as a limited number of independent data sets are available. Two questions must be answered: First, which equation represents the true temperature decrease of the thermal conductivity of the matrix?; and second, what is the true vertical grain thermal conductivity? Unfortunately, the two questions are intimately linked and cannot be answered independently. None of the independent data sets such as log-derived porosities or open-hole temperature measurements in Hole $857 \mathrm{C}$ allows us to determine which of the thermal conductivity profiles represents true in-situ conditions. The calculated porosity profiles in Fig. 4A demonstrate that the models are insensitive to the assumed model conditions. The temperature profiles of all models are well above the open-hole temperature measurements in Hole $857 \mathrm{C}$. The temperature profiles from Model 0 , Model 1, and Model 2 are almost identical, with temperatures at 460 mbsf that are close to the maximum temperature $\left(276^{\circ} \mathrm{C}\right)$ measured in vent fluids in Middle Valley (Shipboard Scientific Party, 1992). It is surprising, however, that the temperature profile of Model 0 , with no temperature-dependent parameters, is identical to the profile of 

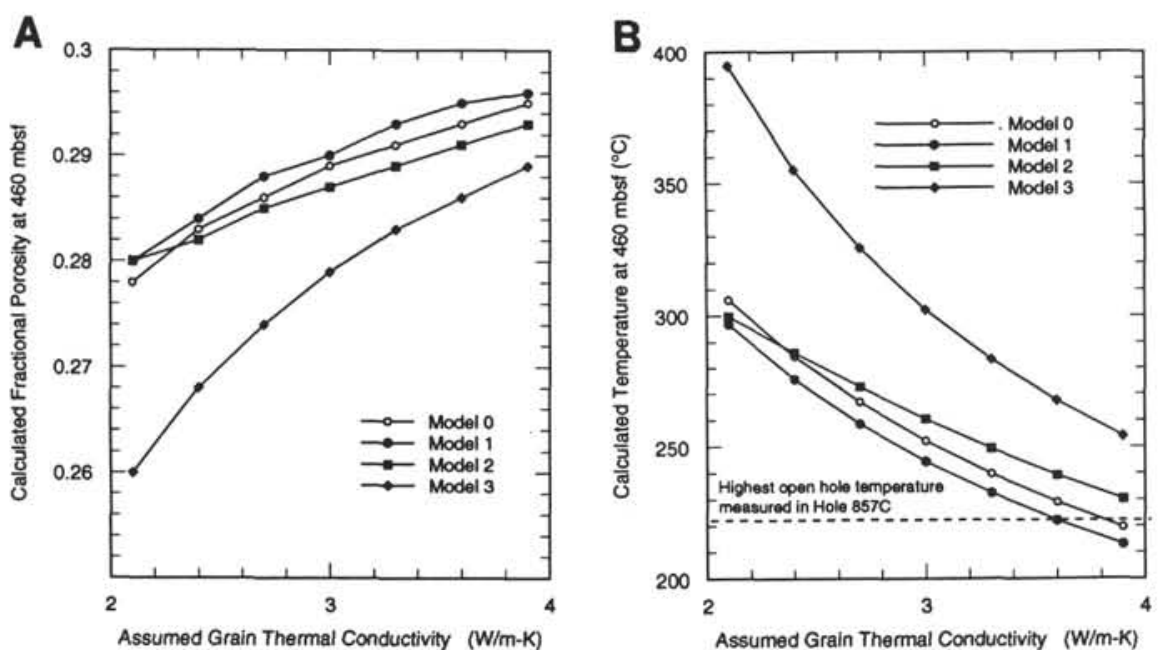

Figure 5. A. Variation of calculated fractional porosity at $460 \mathrm{mbsf}$ (bottom part of the sedimentary section of Hole $857 \mathrm{C}$ ) with assumed grain thermal conductivity. All results show that the variation of grain thermal conductivity has little influence on the porosity in the deepest part of the hole. However, values calculated after Chapman et al. (1984) are significantly lower than all other results. B. Decrease of calculated temperature at $460 \mathrm{mbsf}$ (bottom part of the sedimentary section of Hole $857 \mathrm{C}$ ) with increasing assumed grain thermal conductivity. Temperatures calculated after Chapman et al. (1984) are significantly higher than all other results. The highest temperature of $222^{\circ} \mathrm{C}$, measured in the open Hole $857 \mathrm{C}$ provides a lower bound for the calculated temperatures.

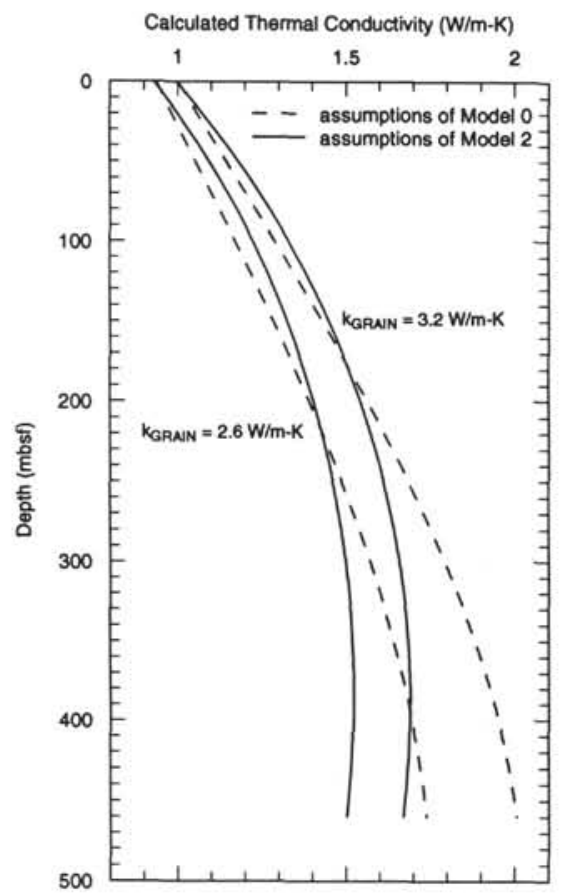

Figure 6. Calculated thermal conductivity profiles based on the assumptions of Model 0 (dashed line) and Model 2 (solid line) for realistic upper and lower bounds of grain thermal conductivities of $2.6 \mathrm{~W} / \mathrm{m}-\mathrm{K}$ and $3.2 \mathrm{~W} / \mathrm{m}-\mathrm{K}$.

Model 2, where both matrix and pore fluid have temperature-dependent thermal parameters. This is the result of the integration in Equation 8 that averages out local differences in the conductivity profiles. The temperature profile of Model 3 is substantially higher than the other profiles due to the significantly lower conductivities over the whole depth range. The temperature of $335^{\circ} \mathrm{C}$ at $460 \mathrm{mbsf}$ is significantly higher than the temperatures of the venting fluids, leading to the conclusion that the thermal conductivity corrections after Chapman et al. (1984) are unrealistically high. Under the assumption of a grain thermal conductivity of $2.6 \mathrm{~W} / \mathrm{m}-\mathrm{K}$, a temperature correction after Sass et al. (1992) (Model 2) most likely gives the most accurate in-situ vertical thermal conductivity profile.

The sensitivity of the results to the assumed grain thermal conductivity is shown in Figures 5A and 5B. As mentioned before, the porosity (Fig. 5A) is insensitive to the assumed grain thermal conductivity and the assumed model conditions. Porosities at $460 \mathrm{mbsf}$ for all models are within a $4 \%$ porosity window, even for a variation of the assumed grain thermal conductivity from $2 \mathrm{~W} / \mathrm{m}-\mathrm{K}$ to $4 \mathrm{~W} / \mathrm{m}-\mathrm{K}$. In contrast, temperatures calculated at $460 \mathrm{mbsf}$ (base of the sediment section) (Fig. 5B) show a much larger variation with grain thermal conductivity. An upper bound for the assumed value $(3.9 \mathrm{~W} / \mathrm{m}-\mathrm{K})$ predicts temperatures at $460 \mathrm{mbsf}$ that are close to the value of $222^{\circ} \mathrm{C}$ measured in the open hole of Hole $857 \mathrm{C}$. The true formation temperature at the depth of $460 \mathrm{mbsf}$ is certainly higher than this value, as the borehole temperature has not yet attained equilibrium with the formation. A comparison of the results from Model 2 and Model 3 shows that the assumed grain thermal conductivities in Model 3 have to be substantially higher than those for Model 2 in order to reach the bottom-hole temperature of $222^{\circ} \mathrm{C}$ measured at $480 \mathrm{mbsf}$.

If one assumes that the temperatures at the base of the sediment section are in the range of temperatures observed at the vent sites (i.e., temperatures of $250-280^{\circ} \mathrm{C}$ ), then the assumed grain thermal conductivity may vary between $2.6 \mathrm{~W} / \mathrm{m}-\mathrm{K}$ and $3.8 \mathrm{~W} / \mathrm{m}-\mathrm{K}$. Grain thermal conductivities of $3.2 \mathrm{~W} / \mathrm{m}-\mathrm{K}$ and higher can only be explained by average volume quartz contents of greater than $40 \%$, which is unlikely due to the inferred sediment composition based on grain size analysis. Therefore the grain thermal conductivities should only vary between 2.6 and $3.2 \mathrm{~W} / \mathrm{m}-\mathrm{K}$. Within this range of conductivities, the most realistic model (i.e., Model 2) will give basement temperatures that well agree with observed vent-fluid temperatures. Figure 6 shows the resulting thermal conductivity profiles calculated with grain thermal conductivities of $2.6 \mathrm{~W} / \mathrm{m}-\mathrm{K}$ and $3.2 \mathrm{~W} / \mathrm{m}-\mathrm{K}$. The profiles provide reasonable lower and upper bounds for the true formation thermal conductivity.

\section{CONCLUSION}

The preceding discussion and the results of the model calculations clearly show that temperature corrections based on Chapman et al. (1984) overestimate the decrease of thermal conductivity with increasing temperature. If one assumes grain densities between 2.6 $\mathrm{W} / \mathrm{m}-\mathrm{K}$ and $3.2 \mathrm{~W} / \mathrm{m}-\mathrm{K}$ and a temperature correction of the conduc- 
tivity after Sass et al. (1992), the resulting temperatures predicted at 460 mbsf, at the top of hydrologic basement, are in good agreement with the observed vent-fluid temperatures. Due to competing effects of decreasing porosity with depth, a temperature-dependent thermal conductivity of the pore-filling liquid, and a steady decrease of thermal conductivity of the matrix with increasing depth and temperature, the most simple model (Model 0) of a binary mixture of seawater and mineral grains with no thermal dependence gives temperatures at 460 mbsf that fortuitously agree with the observations. This surprising coincidence demonstrates that deep temperature measurements provide only a weak constraint for the thermal conductivity profile, due to the integral effect of the underlying formula (Eq. 8). However, including the influence of temperature on thermal conductivity of the grains and the pore-filling fluid using the assumptions of Model 2 with grain conductivities between $2.6 \mathrm{~W} / \mathrm{m}-\mathrm{K}$ and $3.2 \mathrm{~W} / \mathrm{m}-\mathrm{K}$ provides the best estimate for in-situ conditions.

\section{ACKNOWLEDGMENTS}

The authors wish to thank D. Blackwell, E.E. Davis, and G. Vasseur for their thorough reviews, which helped to improve the paper substantially. Thanks are also due to Ms. Speichinger, who carefully typed the manuscript. One of the authors (H.V.) gratefully acknowledges the financial support of the Deutsche Forschungsgmeinschaft for the participation in Leg 139.

\section{REFERENCES ${ }^{*}$}

Birch, F., and Clark, H., 1940. The thermal conductivity of rocks and its dependence upon temperature and composition. Am. J. Sci, 238:529-558, 613-635.

Bischoff, J.L., and Rosenbauer, R.J., 1984. The critical point and two-phase boundary of seawater, $200-500^{\circ} \mathrm{C}$. Earth Planet. Sci. Lett., 68:172-180.

Brigaud, F., Chapman, D.S., and LeDouaran, S., 1990. Estimating thermal conductivity in sedimentary basins using lithologic data and geophysical well logs. AAPG Bull., 74:1459-1477.

Brigaud, F., and Vasseur, G., 1989. Mineralogy, porosity and fluid control on thermal conductivity of sedimentary rocks. Geophys. J., 98:525-542.

Carslaw, H.S., and Jaeger, J.C., 1959. Conduction of Heat in Solids (2nd ed.): Oxford (Clarendon Press).

Chapman, D.S., Keho, T.H., Bauer, M.S., and Picard, M.D., 1984. Heat flow in the Uinta Basin determined from bottom-hole temperature (BHT) data. Geophysics, 49:453-466.

Davis, E.E., Mottl, M.J., Fisher, A.T., et al., 1992. Proc. ODP, Init. Repts., 139: College Station, TX (Ocean Drilling Program).
Davis, E.E., and Villinger, H., 1992. Tectonic and thermal structure of the Middle Valley sedimented rift, northern Juan de Fuca Ridge. In Davis, E.E., Mottl, M.J., Fisher, A.T., et al., Proc. ODP, Init. Repts., 139: College Station, TX (Ocean Drilling Program), 9-41.

Drury, M.J., and Jessop, A.M., 1983. The estimation of rock thermal conductivity from mineral content-an assessment of techniques. Z $\mathrm{bl}$. Geol. Palaontol., Teil I, 1/2:35-48.

Horai, K., and Susaki, J., 1989. The effect of pressure on the thermal conductivity of silicate rocks up to 12 kbar. Phys. Earth Planet. Int., 55:292-305.

Kovalenko, Y.A., and Flanders, S.N., 1991. Thermal conductivity of porous media and soils: a review of soviet investigations. CRREL Spec. Rep., 91-6:1-13.

Morin, R., and Silva, A.J., 1984. The effects of high pressure and high temperature on some physical properties of ocean sediments. J. Geophys. Res., 89:511-526.

Nobes, D.C., Villinger, H., Davis, E.E., and Law, L.K., 1986. Estimation of marine sediment bulk physical properties at depth from seafloor geophysical measurements. J. Geophys. Res., 91:14033-14043.

Phillips, L.S., Igbene, A., Fair, J.A., Ozbek, H., and Tavana, M., 1981. A Technical Databook for Geothermal Energy Utilization: Berkeley, CA (Univ. of California, Lawrence Berkeley Lab.), 1-45.

Sass, J.H., Lachenbruch, A.H., Moses T.H., and Morgan, P., 1992. Heat flow from a scientific research well at Cajon Pass, California. J. Geophys. Res., 97:5017-5030.

Shipboard Scientific Party, 1992. Site 857. In Davis, E.E., Mottl, M.J., Fisher, A.T., et al., Proc. ODP, Init. Repts., 139: College Station, TX (Ocean Drilling Program), 283-429.

Williams, C.F., and Anderson, R.N., 1990. Thermophysical properties of the earth's crust: in-situ measurements from continental and ocean drilling. $J$. Geophys. Res., 95:9209-9236.

Woodside, W., and Messmer, J.H., 1961. Thermal conductivity of porous media in unconsolidated sands. J. Appl. Phys., 32:1688-1706.

Yusufova, V.D., Pepinov, R.I., Nicolayev, V.A., Zokhrabbekova, G.U., Lubcova, N.V., and Tuayev, T.D., 1978. Thermophysical properties of softened seawater and salt solutions over a wide temperature and pressure range. Desalination, 25:269-280.

- Abbreviations for names of organizations and publications in ODP reference lists follow the style given in Chemical Abstracts Service Source Index (published by American Chemical Society).

Date of initial receipt: 22 March 1993

Date of acceptance: 31 August 1993

Ms 139SR-258 